\title{
Identification of citrus expressed sequence tags (ESTs) encoding pleiotropic drug resistance (PDR)-like proteins
}

\author{
Alexandre Morais do Amaral ${ }^{1,2}$, Daniel Saito ${ }^{3}$, Eduardo Fernandes Formighieri ${ }^{4}$, Edenilson Rabello ${ }^{5}$, \\ Adriane N. de Souza ${ }^{5}$, Maria Estela Silva-Stenico ${ }^{5}$ and Siu Mui Tsai ${ }^{5}$ \\ ${ }^{1}$ EMBRAPA Recursos Genéticos e Biotecnologia, Brasília, DF, Brazil. \\ ${ }^{2}$ Centro APTA Citros Sylvio Moreira, Cordeirópolis, Instituto Agronômico de Campinas, SP, Brazil. \\ ${ }^{3}$ Departamento de Diagnóstico Oral, Universidade Estadual de Campinas, Piracicaba, SP, Brazil. \\ ${ }^{4}$ Laboratório de Genômica e Expressão, Universidade Estadual de Campinas, Campinas, SP, Brazil. \\ ${ }^{5}$ Centro de Energia Nuclear na Agricultura, Universidade de São Paulo, Piracicaba, SP, Brazil.
}

\begin{abstract}
Pleiotropic drug resistance (PDR) proteins, a subfamily of the ATP-binding cassette (ABC) transporters, have been recently shown to play a role in plant defense against biotic and abiotic stresses. However, nothing is known about their expression in citrus. To investigate the occurrence of PDR homologues in citrus species, we have surveyed EST sequences from different tissues and conditions of the Citrus Expressed Sequence Tags (CitEST) database, through sequence similarity search analyses and inspections for characteristic PDR domains. Multiple sequence alignments, prediction of transmembrane topology and phylogenetic analysis of PDR-like proteins were additionally performed. This study allowed the identification of nine putative proteins showing characteristic PDR features in citrus species under various conditions, which may indicate a potential correlation between PDRs and stress and metabolism of citrus plants. Moreover, a tissue-specific putative PDR-like protein was found in sweet orange fruits. To our knowledge, this is the first report regarding the identification of citrus ESTs encoding PDR-like proteins as well as the first to identify a putative full $A B C$ transporter with specific expression in fruits.
\end{abstract}

Key words: ABC transporters, CitEST, expressed sequence tag, transcriptome, stress.

Received: September 4, 2006; Accepted: April 2, 2007.

\section{Introduction}

The $\mathrm{ABC}$ transporters, found in bacteria, fungi, plants and animals, form one of the largest protein families and are central to the transport of diverse substances in plants, including those related to resistance to biotic and abiotic stress (Martinoia et al., 2002). In Arabidopsis, the ABC transporter family is considered to be relatively large and composed of 131 members (Jasinski et al., 2003).

Although the $\mathrm{ABC}$ genes have been divided into several subfamilies according to structural features, most of them belong basically to three subfamilies: multidrug resistance (MDR), multidrug resistance-associated protein (MRP), and pleiotropic drug resistance (PDR). Currently, however, very little is known about their roles in plants. These ABC transporters were named according to the ini-

Send correspondence to Alexandre Morais do Amaral. Centro Laboratório de Biotecnologia, APTA Citros Sylvio Moreira, Instituto Agronômico de Campinas, Rod. Anhangüera, km 158, Caixa Postal 4, 13490-970 Cordeirópolis, SP, Brazil. E-mail: aamaral@ cenargen.embrapa.br. tial observation that they confer resistance to various drugs. Such nomenclature can be extremely restrictive, since they may also transport other substrates and be involved in functions other than detoxifying cells. In reality, some members do not even directly participate in drug transport (Jasinski et al., 2003; Crouzet et al., 2006).

All of these ABC transporters subfamilies are highly represented in Arabidopsis and rice: 22 and 17 members of MDR, 15 and 12 members of MRP, and 15 and 23 members of PDR, respectively (Sánchez-Fernández et al., 2001; Jasinski et al., 2003; Crouzet et al., 2006).

MDR proteins are widely distributed from prokaryotes to eukaryotes. Although only a few members have been functionally characterized in plants, their function in human and rodent tissues has been well investigated (Schiengold et al., 2006). In plants, these transporters are highly involved in translocation of alkaloids (Otani et al., 2005) as well as auxin and, as a consequence, in lateral root and root hair development in Arabidopsis (Santelia et al., 2005; Terasaka et al., 2005) and height reduction of maize plants (compact lower stalk internodes) (Multani et al., 2003). 
MRP genes may function in a number of processes, including salt $(\mathrm{NaCl})$ tolerance and detoxification (Lee et al., 2004, Klein et al., 2006), regulation of guard cells aperture and root development (Gaedeke et al., 2001; Klein et $a l ., 2004)$, and vacuolar flavonoid transport (Kitamura et al., 2004).

Representatives of the PDR subfamily have been found in plants and fungi but not in prokaryote or animal species. Most of the PDR genes from plants so far characterized have been shown to be related to responses to abiotic and biotic stress; in fact, pathogens induce their expression, probably resulting in transport of antimicrobial secondary metabolites to the cell surface (Crouzet et al., 2006). Members of the plant PDR subfamily have been implicated in the transport of various compounds, including antifungal agents (van den Brûle and Smart, 2002).

The first plant PDR cDNA to be cloned, SpTUR2, coding for a PDR5-like ABC transporter from the aquatic plant Spirodela polyrrhiza (Smart and Fleming, 1996), was also identified in Arabidopsis, as a response to the diterpenoid antifungal agent sclareol (van den Brûle et al., 2002). Most interestingly, in members of this subfamily of PDR transporters, the nucleotide binding domain (NBD) precedes the hydrophobic transmembrane domain (TMD), as opposed to other full ABC transporters (Crouzet et al., 2006).

TMDs are two highly hydrophobic protein domains that form the channel through which the substrate passes during translocation. They are poorly conserved, which reflects the large diversity of substrates transported; on the other hand, the NBDs show high sequence identity, bound to the cytosolic face of the TMDs and act in both substrate translocation by ATP-binding and hydrolysis (BiemansOldehinkel et al., 2006).

$\mathrm{ABC}$ transporters can be divided into two categories: half-size and full-size transporters. Members of the former share the same structural organization as other ABC transporters, but harbor a single copy of the fusion between NBD and TMD, a category in which the White-Brown Complex subfamily is included (Schmitz et al., 2001; Garcia et al., 2004). On the other hand, full transporters show contiguous core domains on a single multidomain polypeptide (Sánchez-Fernández et al., 2001; BiemansOldehinkel et al., 2006).

Although a significant number of PDR genes were found throughout the complete genome of Arabidopsis and rice, only a few members of this subfamily have been recently investigated in plants. These include: NtPDR3 (iron-deficiency inducible) and NtPDR1 (microbe-elicited) ABC transporters in Nicotiana tabacum (Sasabe et al., 2002; Ducos et al., 2005); NpPDR1, which is involved in both constitutive and jasmonic acid-dependent-induced pathogen defense in N. plumbaginifolia (Stukkens et al., 2005); AtPDR8 and AtPDR12, which, respectively, induce or contribute to hypersensitive cell death upon pathogen infection and resistance to lead in Arabidopsis thaliana (Lee et al., 2005; Kobae et al., 2006; Stein et al., 2006); AtPDR9, which is involved in detoxification of herbicides (2,4-D) in A. thaliana (Ito and Gray, 2006); GmPDR12, which was identified as a salicylic acid-induced gene from soybean cell suspensions (Eichhorn et al., 2006) and Ospdr9, which is induced by the heavy metals cadmium and zinc and hypoxic stress in rice roots (Moons, 2003).

In this study, we identified citrus ESTs encoding PDR-like proteins by search analyses and annotation of the CitEST database.

\section{Materials and Methods}

We have surveyed clones from citrus EST libraries from the CitEST database, supported by MCT-CNPq-Millennium. Altogether, 33 cDNA libraries were constructed from nine different citrus species and diverse conditions (including environment- and pathogen-challenged plants), from which 5'-sequenced ESTs from 242,790 valid reads (transcripts) were generated. Because EST databases may contain many overlapping sequences from the same gene, the ESTs were clustered using the CAP3 program with a 40-base pair overlap and $80 \%$ identity criterion (Huang and Madan, 1999). Consensus sequences were periodically compared using BLASTX (Altschul et al., 1990) $\left(E=10^{-5}\right)$ to the NCBI translated nonredundant (nr) database.

Initially, the CitEST database was searched for PDR homologues, based on sequence similarity to the deduced amino acid sequences from the SpTUR2 protein, the first plant PDR to be cloned (Smart and Fleming, 1996), and all PDR members of $A$. thaliana (AtPDR1 through AtPDR15) through BLAST analyses. As an additional procedure, the database was repeatedly searched during the course of this inventory with the keyword "PDR." The presence of Walker A and B motifs and $\mathrm{ABC}$ signature was used as complementary identification parameters: sequences (clusters) that did not show at least a single copy were rejected.

The multiple sequence alignment of the obtained sequences and other plant PDRs was performed by the CLUSTAL W program (Higgins et al., 1996). Final alignment was visually inspected and manually corrected. In addition, the HMMTOP program (Tusnády and Simon, 2001) was used for prediction of transmembrane helices and topology of proteins.

Phylogenetic analysis of the citrus putative PDR-like transporters along with 15 representative sequences from $A$. thaliana was conducted with the Molecular Evolutionary Genetics Analysis (MEGA) software version 3.1 (Kumar et al., 2004). The minimum evolution method was used, with a total of 1,000 bootstrap replicate trees.

To calculate a probability value for each gene in each two-library comparison, the AC test (Audic and Claverie, 1997) was used; i.e., a "digital analysis of gene expression" was performed taking into account the total number of transcripts retrieved from each of the libraries and the statistical significance, with a confidence of $95 \%$. 


\section{Results and Discussion}

Overall, the analysis of the CitEST database revealed 230 PDR-related sequences, which were assembled into 29 contigs and 30 singlets (sequences that did not fit into any contig). The selected transcripts were then grouped on the basis of citrus species. All groupings were performed manually. The species-directed approach rendered nine clusters (sequences in a cluster are assumed to represent the same gene) that showed high BLAST similarity values $\left(E=2 \mathrm{e}^{-98}\right)$ and presence of the characteristic domains. The clusters included four citrus species (C. sinensis, C. reticulata, P. trifoliata, and C. limonia) and various EST libraries and showed best matches with PDR homologues from $N$. tabacum [NtPDR1 (Q76CU2), NtPDR2 (BAD07484, AB109389), and NtPDR3 (Q5W274)] and A. thaliana [AtPDR4 (DAA00872), AtPDR6 (AAD24623), AtPDR11 (DAA00879), and AtPDR12 (NP 173005)] (Table 1). Indeed, two of the citrus clusters were formed by only one transcript; i.e., they represent singlets. The multiple alignment of all clusters and PDR homologues did not reveal any full-length PDRs (Figure 1). The alignment showed that all citrus PDR-like clusters as well as the NtPDR2 homologue lacked the Walker $\mathrm{A}$ and $\mathrm{B}$ boxes and the $\mathrm{ABC}$ signature in $\mathrm{N}$-terminal region. On the other hand, they contain perfectly conserved Walker A motifs with the Arabidopsis C-terminal consensus of GVSGAGKT. Also, the C-terminal PDR Walker B box [I(ILV)F(ML)D] and ABC signature [L(ST)TEQRLTIA] fit the consensus perfectly, with the exception of CsPDR4, where one residue does not fit the consensus. Obviously, the topology of motifs predicted by the computer program was affected by incomplete sequences (Figure 2).

Since there is no report on PDR-like proteins in citrus to date, and in line with a recently suggested nomenclature system (van den Brûle and Smart, 2002; Eichhorn et al., 2006), we suggested a nomenclature for these homologues which took into consideration the citrus species and the phylogenetic tree (Figure 3), which was generated with predicted PDR proteins from $A$. thaliana and all CitEST PDR- like candidates as follows: CAS-CS-107920, CsPDR12; CAS-CS-111457, CsPDR11; CAS-CS-104504, CsPDR4; CAS-CS-109837, CsPDR13; CAS-CR-202176, CrPDR12; CAS-CR-209514, CrPDR11; CAS-CR-204968, CrPDR13; CAS-PT-307851, PtPDR9; and CAS-CL-701595, CIPDR6.

Only seven of the nine citrus clusters displayed typical TMD of $\mathrm{ABC}$ transporters. In fact, unlike other full $\mathrm{ABC}$ transporters (MDR and MRP), all citrus clusters with TMD showed the reverse configuration expected from PDR proteins (NBD preceding TMD). Although neither CrPDR11 nor PtPDR9 showed TMDs, we assumed both sequences as representative of PDR-like proteins due to the high homology to the PDR transporters NtPDR2 and NtPDR3, respectively, as well as due to the presence of the complete sequences of Walker $\mathrm{A}$ and $\mathrm{B}$ motifs and the $\mathrm{ABC}$ signature.

Alignment of two sequences using BLAST engine for local alignment (Tatusova and Madden, 1999) between all 29 AtWBC (A. thaliana White-Brown Complex) transporters from the GenBank and all citrus PDR candidates found much lower similarities as compared to AtPDR transporters.

A quantitative method for the analysis of transcript frequencies and detection of differences among libraries was used (Audic and Claverie, 1997) during systematic pairwise comparisons conducted between CitEST libraries, which revealed some very interesting characteristics regarding gene expression in sweet orange (Table 2). From this analysis, we identified two genes with tag differences between libraries (Pera sweet orange varieties and developmental stage of fruits) that were significant at $p \leq 0.05$. In fact, three additional comparisons with $\mathrm{p}$ values between 0.05 and 0.07 also were considered for further analysis.

Two clusters of the citrus database (CsPDR12 and CsPDR13) were constructed from sweet orange $(C$. sinensis) transcripts that matched the NtPDR1 gene. These clusters comprise transcripts from different conditions (Table 3). Remarkably, the citrus homologue CsPDR13 was constructed exclusively with cDNA from sweet orange fruits. Although NtWBC1, a half transporter of the WhiteBrown subfamily found in tobacco, was the first $\mathrm{ABC}$

Table 1 - Pleiotropic drug resistance (PDR) transporters found in the CitEST database.

\begin{tabular}{|c|c|c|c|c|c|c|}
\hline Cluster & Species & Length (aa) & Accession & Gene name and organism & E-value & Identity $(\%)$ \\
\hline CsPDR12 & CS & 624 & Q76CU2 & NtPDR1 (Nicotiana tabacum) & 0.0 & 81 \\
\hline CsPDR11 & CS & 522 & Q7PC84 & AtPDR11 (Arabidopsis thaliana) & 0.0 & 68 \\
\hline CsPDR4 & $\mathrm{CS}$ & 468 & DAA00872 & AtPDR4 (A. thaliana) & $8 \mathrm{e}^{-139}$ & 89 \\
\hline CsPDR13 & CS & 552 & Q76CU2 & NtPDR1 (N. tabacum) & $4 e^{-127}$ & 89 \\
\hline CrPDR12 & $\mathrm{CR}$ & 337 & NP_173005 & AtPDR12 (A. thaliana) & 0.0 & 73 \\
\hline CrPDR11 & $\mathrm{CR}$ & 310 & AB109389 & NtPDR2 (N. tabacum) & $2 \mathrm{e}^{-102}$ & 72 \\
\hline CrPDR13 & $\mathrm{CR}$ & 687 & NP_173005 & AtPDR12 (A. thaliana) & 0.0 & 73 \\
\hline PtPDR9 & PT & 304 & Q5W274 & NtPDR3 (N. tabacum) & $4 e^{-110}$ & 79 \\
\hline CIPDR6 & $\mathrm{CL}$ & 486 & DAA00874 & AtPDR6 (A. thaliana) & 0.0 & 73 \\
\hline
\end{tabular}

1- CS - Citrus sinensis, CR - C. reticulata, PT - Poncirus trifoliata and CL - C. limonia. 


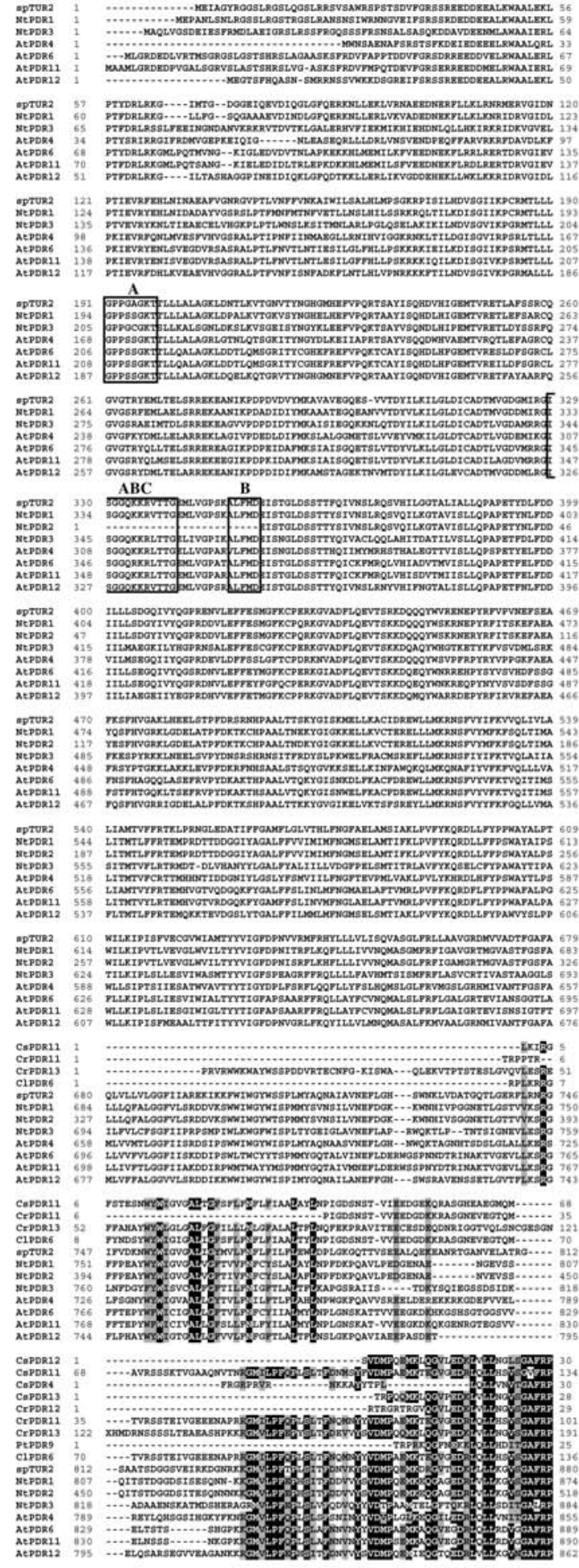

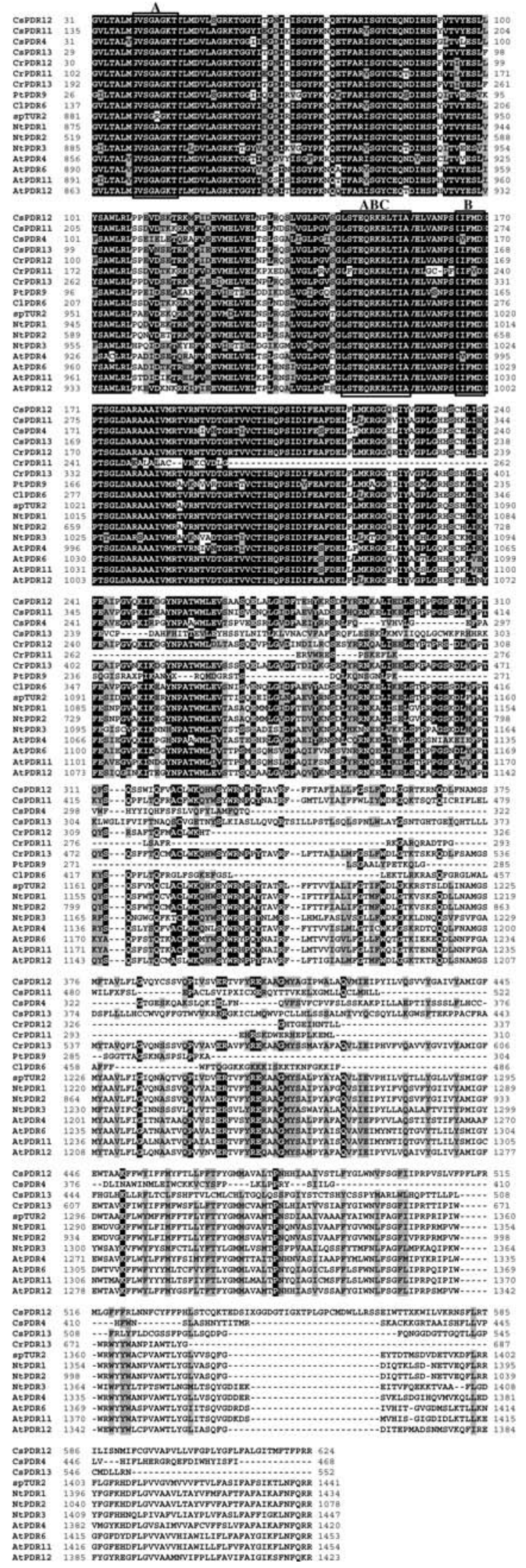

Figure 1 - Multiple alignment of the conserved domain in PDR proteins of CitEST containing ABC signature and Walker A and B motifs, aligned to plant PDRs SpTUR2 (accession no. O24367), NtPDR1 (Q76CU2), NtPDR2 (BAD07484), NtPDR3 (Q5W274), AtPDR4 (DAA00872), AtPDR6 (AAD24623), AtPDR11 (DAA00879), and AtPDR12 (NP 173005), using the CLUSTAL W program (Higgins et al., 1996). 

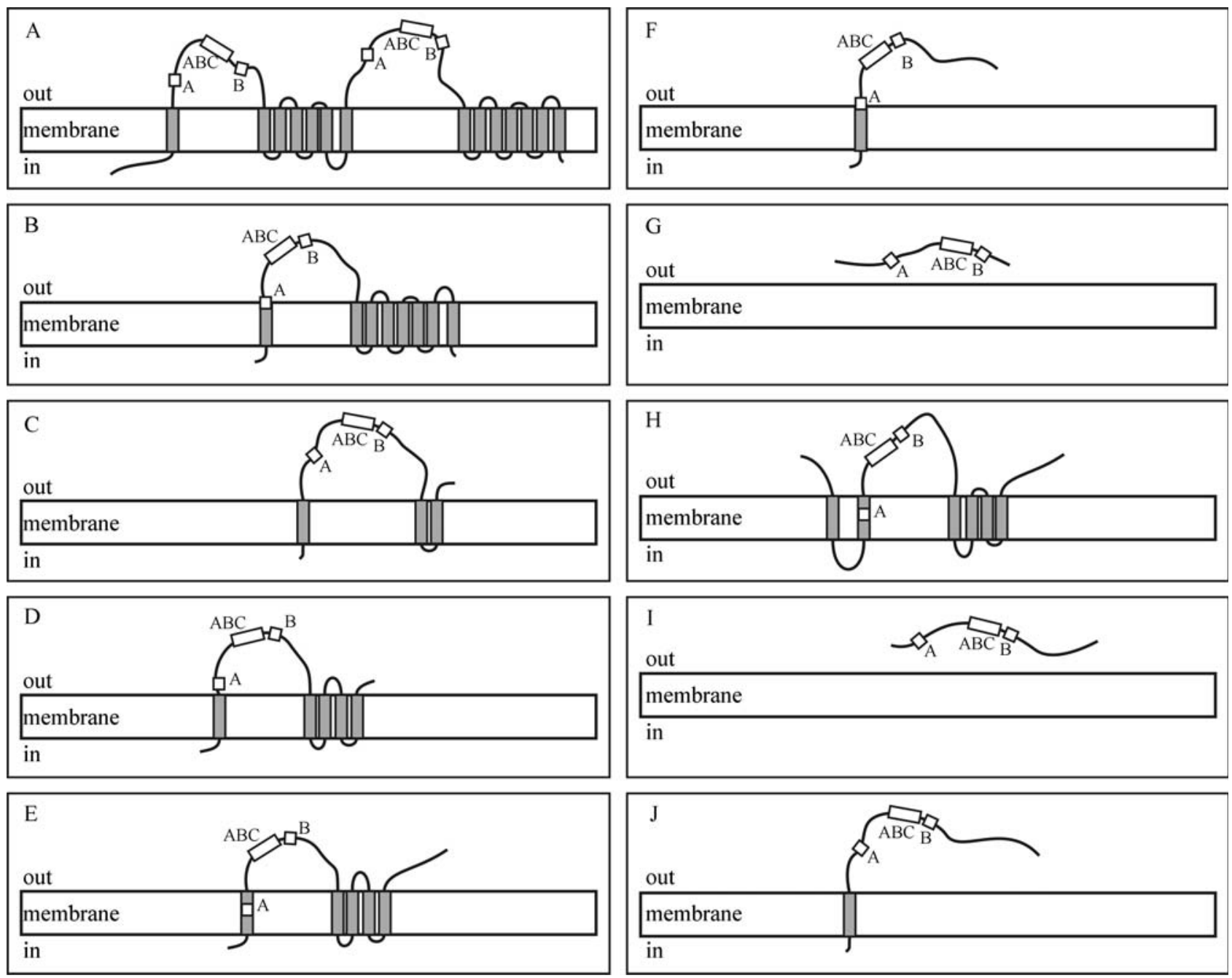

Figure 2 - Organization of typical PDR proteins and their comparison with the CitEST clusters, showing the transmembrane domains (TMD) and the nucleotide binding domain (NBD), which includes the Walker A and B motifs and the ABC signature. [A: SpTUR2 (accession no. O24367), B: CsPDR12, C: CsPDR11, D: CsPDR4, E: CsPDR13, F: CrPDR12, G: CrPDR11, H: CrPDR13, I: PtPDR9, and J: ClPDR6].

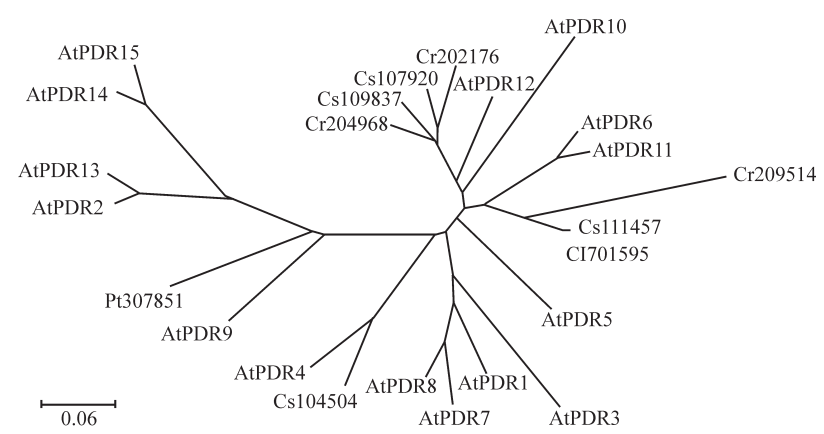

Figure 3 - Phylogenetic interrelationships of nine predicted PDR-like transporters identified in citrus species and 15 PDR-like representatives from $A$. thaliana. The unrooted tree was constructed by the MEGA 3.1 software (Kumar et al., 2004), according to the minimum evolution method (Rzhetsky and Nei, 1993) with 1,000 bootstrap replicate trees, based on a preliminary neighbor - joining tree (Saitou and Nei, 1987). The scale bar represents the number of nucleotide substitutions per site.

transporter gene with specific expression in plant reproductive organs to be identified (Otsu et al., 2004), to our knowledge, CsPDR13 is the first full ABC transporter candidate with specific expression in fruit identified to date.

The deduced amino acid sequence of CsPDR13 is homologous to NtPDR1 with $89 \%$ identical residues, which rates the highest identity to plant PDR proteins as compared to the other citrus PDR-like proteins. However, this citrus homologue originated from a cDNA library not stresschallenged (i.e., apparently healthy plant) thus suggesting a function of this homologue which might be not related to stress response. Although it is well known that levels of many compounds accumulate during citrus fruit ripening and in different stages of growth (Kato et al., 2004; Cercos et al., 2006; Kato et al., 2006), specific ABC transporters that participate in this process have not previously been identified. Additionally, the analysis of the transcript frequencies suggests that a higher expression of this gene occurs early during fruit growth.

On the other hand, the cluster CsPDR12 was formed with transcripts originating from a number of tissues and 
Table 2 - Differentially expressed PDR-like genes in citrus EST libraries detected by electronic subtraction.

\begin{tabular}{|c|c|c|c|c|c|c|c|}
\hline \multirow[t]{3}{*}{ Cluster } & \multicolumn{2}{|l|}{ Libraries } & \multicolumn{4}{|c|}{ Number of ESTs } & \multirow[t]{3}{*}{$\mathrm{p}$ value $^{1}$} \\
\hline & \multirow[b]{2}{*}{ N1 } & \multirow[b]{2}{*}{$\mathrm{N} 2$} & \multicolumn{2}{|c|}{ Per cluster } & \multicolumn{2}{|c|}{ Per library } & \\
\hline & & & N1 & $\mathrm{N} 2$ & N1 & $\mathrm{N} 2$ & \\
\hline \multicolumn{8}{|c|}{ CsPDR12 } \\
\hline & \multirow{7}{*}{$\begin{array}{l}\text { Leaves from field- } \\
\text { grown Pera Olimpia } \\
\text { orange trees }\end{array}$} & $\begin{array}{l}\text { Leaves from greenhouse-grown Pera sweet } \\
\text { orange trees }\end{array}$ & \multirow{7}{*}{3} & 1 & \multirow{7}{*}{2,603} & 9,536 & 0.02434 \\
\hline & & $\begin{array}{l}\text { Leaves from greenhouse-grown Pera sweet } \\
\text { orange trees infected with Xylella fastidiosa }\end{array}$ & & 1 & & 6,408 & 0.04876 \\
\hline & & $\begin{array}{l}\text { Leaves from } 8 \text {-month old Pera sweet orange trees, } \\
30 \text { days after inoculation (dai) with } X \text {. fastidiosa }\end{array}$ & & 2 & & 9,243 & 0.05040 \\
\hline & & $\begin{array}{l}\text { Peel of fruits, } 2.5 \mathrm{~cm} \text { in diameter, from } \\
\text { greenhouse-grown Pera sweet orange trees }\end{array}$ & & 1 & & 8,760 & 0.02858 \\
\hline & & $\begin{array}{l}\text { Peel of fruits, } 7 \mathrm{~cm} \text { in diameter, from } \\
\text { greenhouse-grown Pera sweet orange trees }\end{array}$ & & 2 & & 8,195 & 0.06124 \\
\hline & & $\begin{array}{l}\text { Peel of fruits, } 8 \mathrm{~cm} \text { in diameter, from } \\
\text { greenhouse-grown Pera sweet orange trees }\end{array}$ & & 1 & & 7,330 & 0.03920 \\
\hline & & $\begin{array}{l}\text { Peel of fruits, } 9 \mathrm{~cm} \text { in diameter, from } \\
\text { greenhouse-grown Pera sweet orange trees }\end{array}$ & & 2 & & 8,653 & 0.05618 \\
\hline \multicolumn{8}{|c|}{ CsPDR13 } \\
\hline & \multirow{2}{*}{$\begin{array}{l}\text { Peel of fruits, } 9 \mathrm{~cm} \\
\text { in diameter, from } \\
\text { greenhouse-grown } \\
\text { plant }\end{array}$} & $\begin{array}{l}\text { Peel of fruits, } 2.5 \mathrm{~cm} \text { in diameter, from green- } \\
\text { house-grown plant }\end{array}$ & \multirow[b]{2}{*}{1} & 5 & \multirow[b]{2}{*}{8,653} & 8,760 & 0.04833 \\
\hline & & $\begin{array}{l}\text { Peel of fruits, } 7 \mathrm{~cm} \text { in diameter, from green- } \\
\text { house-grown plant }\end{array}$ & & 5 & & 8,195 & 0.04081 \\
\hline
\end{tabular}

1 - $\mathrm{p}$ value for the Audic and Claverie test.

environmental conditions, including fruits, Xylella-infected and healthy leaves, grown either under greenhouse or in the field. Although CsPDR12 shares high similarity of deduced amino acid sequences with NtPDR1, a microbeelicited $\mathrm{ABC}$ transporter in tobacco and the first plant PDR to be induced by a microbial elicitor (Sasabe et al., 2002; Ducos et al., 2005), the role played by this putative protein in citrus is still unclear, especially because CsPDR12 includes transcripts from various conditions. However, remarkably, the highest contribution in number of transcripts for this cluster originated from adult plants of Olimpia, a clonal variation of Pera sweet orange that is regarded as a productive plant in the Northern region (warm climate) of the citrus industry in São Paulo State, the largest area of citrus production in Brazil. In contrast, the clone shows a very low yield in the South (temperate weather) of the same state. The relationship, if any, between CsPDR12, Olimpia sweet orange and environmental conditions is still not clear and merits more studies.

The PDR-candidate CsPDR11 matched the AtPDR11 gene and was constructed with transcripts originating from the following libraries: leaves from 8-month old plants, 30 days after inoculation (dai) with Xylella fastidiosa, leaves from greenhouse-grown plants inoculated with CiLV, and peel of fruits $2.5 \mathrm{~cm}$ and $8 \mathrm{~cm}$ in diameter, both from greenhouse-grown plants. Although there is no experimental information regarding AtPDR11 function, its similarity with another PDR-homologue (OspDR9) found in rice and induced by heavy metals such as zinc $(\mathrm{Zn})$, nickel $(\mathrm{Ni})$ and cobalt (Co) (Moons, 2003) supports a hypothesis that it might be a general defense protein. In fact, the same similarity was found for CsPDR4, a PDR-like sequence found in $C$. sinensis libraries, which showed best match with AtPDR4. The cluster included transcripts from diverse libraries of plants grown under greenhouse conditions: leaves from trees infected with X. fastidiosa, the second pair of leaves from seedling and fruits.

The clusters CrPDR11 and CrPDR12, found in Ponkan mandarin trees $(C$. reticulata), matched the NtPDR2 gene from $N$. tabacum. CrPDR12 is a cluster constructed with transcripts from leaves collected from plants 30 dai with $X$. fastidiosa, grown in phytotron and a transcript from peel of fruits $1 \mathrm{~cm}$ in diameter, from field-grown trees. On the other hand, the singlet CrPDR11 was formed from leaves of a healthy Ponkan mandarin grown in phytotron. Although there is no function identified for NtPDR2 to date, its high identity with NtPDR1 might indicate a participation in stress response (Sasabe et al., 2002). As a matter of fact, the putative PDR protein NtPDR2 lacks the first conserved domains containing $\mathrm{ABC}$ signature and Walker $\mathrm{A}$ and $\mathrm{B}$ motifs.

Transcripts from three C. reticulata libraries (leaves from healthy plants grown in phytotron, leaves collected from plant 60 dai with $X$. fastidiosa, grown in phytotron, and peel of fruits $1 \mathrm{~cm}$ in diameter from field-grown trees) rendered the cluster CrPDR13 and matched the AtPDR12 gene, which is phylogenetically close to GmPDR12, a salicylic acid-induced gene from soybean cell suspensions (Eichhorn et al., 2006). However, the transcript expression 
Table 3 - List of citrus cDNA libraries and PDR homologues (normalized for 10,000 ESTs per library).

\begin{tabular}{|c|c|c|c|c|c|c|c|c|c|c|}
\hline \multirow[t]{2}{*}{ Species $^{1}$} & \multirow[t]{2}{*}{ Library } & \multicolumn{9}{|c|}{ Number of ESTs per PDR homologue } \\
\hline & & 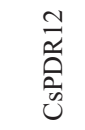 & 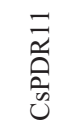 & $\begin{array}{l}\stackrel{+}{a} \\
\frac{1}{0} \\
\tilde{v}\end{array}$ & 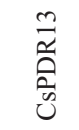 & 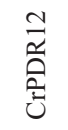 & $\begin{array}{l}\overline{\vec{a}} \\
\text { 宅 }\end{array}$ & $\begin{array}{l}\stackrel{m}{\vec{a}} \\
\text { 宅 }\end{array}$ & 竞 & 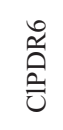 \\
\hline $\mathrm{CS}$ & Leaves from greenhouse-grown trees & 1.05 & & & & & & & & \\
\hline $\mathrm{CS}$ & Leaves from greenhouse-grown trees infected with Xylella fastidiosa & 1.56 & & 1.56 & & & & & & \\
\hline $\mathrm{CS}$ & $\begin{array}{l}\text { Leaves from 8-month old plants, } 30 \text { days after inoculation (dai) with } \\
\text { X. fastidiosa }\end{array}$ & 2.16 & 2.16 & & & & & & & \\
\hline CS & Leaves from greenhouse-grown plants inoculated with CiLV & & 2.06 & & & & & & & \\
\hline $\mathrm{CS}$ & Second pair of leaves from greenhouse-grown seedling & & & 2.03 & & & & & & \\
\hline $\mathrm{CS}$ & Bark from greenhouse-grown plants & & & & & & & & & \\
\hline $\mathrm{CS}$ & Peel of fruits, $1 \mathrm{~cm}$ in diameter, from greenhouse-grown plant & & & & & & & & & \\
\hline $\mathrm{CS}$ & Peel of fruits, $2.5 \mathrm{~cm}$ in diameter, from greenhouse-grown plant & 1.14 & 1.14 & & 5.7 & & & & & \\
\hline $\mathrm{CS}$ & Peel of fruits, $5 \mathrm{~cm}$ in diameter, from greenhouse-grown plant & & & & & & & & & \\
\hline $\mathrm{CS}$ & Peel of fruits, $7 \mathrm{~cm}$ in diameter, from greenhouse-grown plant & 2.44 & & & 6.1 & & & & & \\
\hline $\mathrm{CS}$ & Peel of fruits, $8 \mathrm{~cm}$ in diameter, from greenhouse-grown plant & 1.36 & 1.36 & & & & & & & \\
\hline $\mathrm{CS}$ & Peel of fruits, $9 \mathrm{~cm}$ in diameter, from greenhouse-grown plant & 2.31 & & 1.16 & 1.16 & & & & & \\
\hline $\mathrm{CS}$ & Flowers at different developmental stages & & & & & & & & & \\
\hline $\mathrm{CS}$ & Leaves from field-grown trees & & & & & & & & & \\
\hline $\mathrm{CS}^{2}$ & Leaves from field-grown trees & 11.52 & & & & & & & & \\
\hline $\mathrm{CR}$ & Leaves from healthy plant, grown in phytotron & & & & & & 1.18 & 2.36 & & \\
\hline $\mathrm{CR}$ & Leaves from plants 30 dai with $X$. fastidios $a$, grown in phytotron & & & & & 2.37 & & & & \\
\hline $\mathrm{CR}$ & Leaves from plants 60 dai with $X$. fastidios $a$, grown in phytotron & & & & & & & 2.35 & & \\
\hline $\mathrm{CR}$ & Peel of fruits, $1 \mathrm{~cm}$ in diameter, from field-grown trees & & & & & 1.07 & & 2.14 & & \\
\hline $\mathrm{CR}$ & Peel of fruits, $2.5 \mathrm{~cm}$ in diameter, from field-grown trees & & & & & & & & & \\
\hline $\mathrm{CR}$ & Peel of fruits, $5 \mathrm{~cm}$ in diameter, from field-grown trees & & & & & & & & & \\
\hline PT & Leaves from greenhouse-grown plants & & & & & & & & & \\
\hline PT & Leaves from plants inoculated with CTV, grown in greenhouse & & & & & & & & 1.12 & \\
\hline PT & Bark from greenhouse-grown plants & & & & & & & & & \\
\hline PT & $\begin{array}{l}\text { Bark from plants inoculated with Phytophthora parasitica, grown in } \\
\text { greenhouse }\end{array}$ & & & & & & & & & \\
\hline PT & Seeds from fruits at different developmental stages & & & & & & & & & \\
\hline $\mathrm{CA}$ & Leaves from field-grown plants & & & & & & & & & \\
\hline $\mathrm{CG}$ & Leaves from greenhouse-grown plants & & & & & & & & & \\
\hline $\mathrm{LT}$ & Leaves from greenhouse-grown plants & & & & & & & & & \\
\hline $\mathrm{CL}$ & Roots from seedlings grown in nutritive solution & & & & & & & & & 5.52 \\
\hline CL & Roots from seedlings after drought stress & & & & & & & & & 3.57 \\
\hline $\mathrm{CM}$ & Leaves collected from greenhouse-grown plants 2 dai with CiLV & & & & & & & & & \\
\hline TS & Bark from greenhouse-grown plants & & & & & & & & & \\
\hline Total & & 23.54 & 6.72 & 4.75 & 12.96 & 3.44 & 1.18 & 6.85 & 1.12 & 9.09 \\
\hline
\end{tabular}

1- CS - Citrus sinensis var. Pera, CR - C. reticulata var. Ponkan, PT - Poncirus trifoliata, CA - C. aurantium, CG - C. aurantifolia, LT - C. latifolia, CL C. limonia, CM - C. limettioides, TS - C. sunki. 2- C. sinensis var. Olimpia.

analysis indicates no differences between "healthy" and Xylella-infected libraries.

The AtPDR 12 and its homologues are the experimentally best-studied PDR proteins from plants to date (Campbell et al., 2003; Lee et al., 2005; Crouzet et al., 2006). AtPDR12 expression in Arabidopsis is induced by fungaland bacterial-pathogen inoculation (Alternaria brassicicola and Sclerotinia sclerotium and the bacterium Pseudomonas syringae pv. tomato) or defense-related signal molecules like methyl jasmonate, ethylene, salicylic acid and jasmonic acid (Campbell et al., 2003).
Although little is known about the substrates that are transported by this protein, in ABC transporter AtPDR12knockout $A$. thaliana plants, a higher (and toxic) content of lead was identified in the roots, while wild plants showed a lead detoxification mechanism (Lee et al., 2005). It is suggested that, in contrast to fungal PDR transporters, which show a large substrate spectrum, plant PDR transporters might have much higher substrate specificity (van den Brûle et al., 2002).

Interestingly, the cluster PtPDR9, which matched the NtPDR3 gene, originated from a single transcript from a li- 
brary constructed from leaves of $P$. trifoliata plants inoculated with CTV and grown in greenhouse. As a matter of fact, P. trifoliata is a relative of Citrus that shows a putative single dominant gene (Ctv) that is highly associated to the resistance against CTV (Bernet et al., 2004; Rai, 2006). In tobacco, NtPDR3 expression was shown to be induced by iron deficiency and plant defense-related compounds, such as salicylic acid (SA) and methyl jasmonate (MJ) (Ducos et al., 2005). Moreover, in other plants, PDR transporters were also found to be responsive to these chemical signals: AtPDR12 (SA), NtPDR12 (MJ), NpABC1 (MJ), and GmPDR12 (SA and MJ) (Sasabe et al., 2002; Campbell et al., 2003; Grec et al., 2003; Eichhorn et al., 2006). Both SA and MJ molecules have been shown to play a role as chemical signal compounds during plant defense against pathogens, by regulating the signaling pathways associated with defense responses (Dong, 1998; Reymond and Farmer, 1998). In fact, these PDR transporters could function by transporting substrates that are excreted onto the plant surface and act as antimicrobial agents (Jasinski et al., 2003; van den Brûle and Smart, 2002).

CIPDR6 matched the AtPDR6 gene from A. thaliana, to which no functional role has been assigned so far. The cluster was formed by transcripts originating from roots of Rangpur lime (C. limonia) seedlings grown either in nutritive solution or under drought stress. C. limonia is the main rootstock used in the Brazilian citrus industry, especially due to its high tolerance to water deficit. However, there is no clear evidence of PDR6 participation during response to stress or differential expression of these libraries.

These analyses provide critical information to help identify new target genes for further investigation and functional analysis, which will lead to a better understanding of the mechanisms that govern a number of cellular processes, including stress tolerance, and may open up new ways to improve the agronomic properties of citrus plants. Therefore, further studies are necessary to gain a better understanding of the substrates of these citrus PDR-like proteins under specific conditions.

Finally, taking these data together we conclude that at least nine putative PDR proteins may be present in citrus tissues. Given the current paucity of knowledge on PDR proteins activity in citrus, additional analyses will be conducted to clarify the roles played by them in plant cell physiology.

\section{Acknowledgments}

The authors are grateful to the Millennium Institute (MCT/CNPq) (62.0054/01-8) and FAPESP (2005/007199) for financial support. We would like to thank Maria Luisa P. N. Targon for the construction of cDNA libraries and Marcelo Reis for bioinformatics support. We would also like to thank Kleber Borges, Carolina Munari and Juliana Mendonça for their technical help.

\section{References}

Altschul SF, Gish W, Miller W, Myers EW and Lipman DJ (1990) Basic local alignment search tool. J Mol Biol 215:403-410.

Audic S and Claverie JM (1997) The significance of digital gene expression profiles. Genome Research 7:986-995.

Bernet GP, Breto MP and Asins MJ (2004) Expressed sequence enrichment for candidate gene analysis of citrus tristeza virus resistance. Theor Appl Genet 108:592-602.

Biemans-Oldehinkel E, Doeven MK and Poolman B (2006) ABC transporter architecture and regulatory roles of accessory domains. FEBS Lett 580:1023-1035.

Campbell EJ, Schenk PM, Kazan K, Penninckx IA, Anderson JP, Maclean DJ, Cammue BP, Ebert PR and Manners JM (2003) Pathogen-responsive expression of a putative ATP-binding cassette transporter gene conferring resistance to the diterpenoid sclareol is regulated by multiple defense signaling pathways in Arabidopsis. Plant Physiol 133:1272-1284.

Cercos M, Soler G, Iglesias DJ, Gadea J, Forment J and Talon M (2006) Global analysis of gene expression during development and ripening of citrus fruit flesh. A proposed mechanism for citric acid utilization. Plant Mol Biol 62:513-527.

Crouzet J, Trombik T, Fraysse AS and Boutry M (2006) Organization and function of the plant pleiotropic drug resistance ABC transporter family. FEBS Lett 580:1123-1130.

Dong X (1998) SA, JA, ethylene, and disease resistance in plants. Curr Opin Plant Biol 1:316-323.

Ducos E, Fraysse S and Boutry M (2005) NtPDR3, an irondeficiency inducible ABC transporter in Nicotiana tabacum. FEBS Lett 579:6791-6795.

Eichhorn H, Klinghammer M, Becht P and Tenhaken R (2006) Isolation of a novel ABC-transporter gene from soybean induced by salicylic acid. J Exp Bot 57:2193-2201.

Gaedeke N, Klein M, Kolukisaoglu U, Forestier C, Muller A, Ansorge M, Becker D, Mamnun Y, Kuchler K, Schulz B, et al. (2001) The Arabidopsis thaliana ABC transporter AtMRP5 controls root development and stomata movement. EMBO J 20:1875-1887.

Garcia O, Bouige P, Forestier C and Dassa E (2004) Inventory and comparative analysis of rice and Arabidopsis ATP-binding cassette (ABC) systems. J Mol Biol 343:249-265.

Grec S, Vanham D, de Ribaucourt JC, Purnelle B and Boutry M (2003) Identification of regulatory sequence elements within the transcription promoter region of $N p A B C 1$, a gene encoding a plant $\mathrm{ABC}$ transporter induced by diterpenes. Plant J 35:237-250.

Higgins DG, Thompson JD and Gibson TJ (1996) Using CLUSTAL for multiple sequence alignments. Methods Enzymol 266:383-402.

Huang XQ and Madan A (1999) CAP3: A DNA sequence assembly program. Genome Res 9:868-877.

Ito $\mathrm{H}$ and Gray WM (2006) A gain-of-function mutation in the Arabidopsis pleiotropic drug resistance transporter PDR9 confers resistance to auxinic herbicides. Plant Physiol 142:63-74.

Jasinski M, Ducos E, Martinoia E and Boutry M (2003) The ATP-binding cassette transporters: Structure, function, and gene family comparison between rice and Arabidopsis. Plant Physiol 131:1169-1177.

Kato M, Ikoma Y, Matsumoto H, Sugiura M, Hyodo H and Yano M (2004) Accumulation of carotenoids and expression of carotenoid biosynthetic genes during maturation in citrus fruit. Plant Physiol 134:824-837. 
Kato M, Matsumoto H, Ikoma Y, Okuda H and Yano M (2006) The role of carotenoid cleavage dioxygenases in the regulation of carotenoid profiles during maturation in citrus fruit. $\mathrm{J}$ Exp Bot 57:2153-2164.

Kitamura S, Shikazono N and Tanaka A (2004) Transparent TESTA 19 is involved in the accumulation of both anthocyanins and proanthocyanidins in Arabidopsis. Plant $\mathrm{J}$ 37:104-114.

Klein M, Geisler M, Suh SJ, Kolukisaoglu HU, Azevedo L, Plaza S, Curtis MD, Richter A, Weder B, Schulz B, et al. (2004) Disruption of AtMRP4, a guard cell plasma membrane ABCCtype $\mathrm{ABC}$ transporter, leads to deregulation of stomatal opening and increased drought susceptibility. Plant J 39:219-236.

Klein M, Burla B and Martinoia E (2006) The multidrug resistance-associated protein (MRP/ABCC) subfamily of ATPbinding cassette transporters in plants. FEBS Lett 580:1112-1122.

Kobae Y, Sekino T, Yoshioka H, Nakagawa T, Martinoia E and Maeshima M (2006) Loss of AtPDR8, a plasma membrane ABC transporter of Arabidopsis thaliana, causes hypersensitive cell death upon pathogen infection. Plant Cell Physiol 47:309-318.

Kumar S, Tamura K and Nei M (2004) MEGA3: Integrated software for molecular evolutionary genetics analysis and sequence alignment. Brief Bioinform 5:150-163.

Lee EK, Kwon M, Ko J-H, Yi H, Hwang MG, Chang S and Cho MH (2004) Binding of sulfonylurea by AtMRP5, an Arabidopsis multidrug resistance-related protein that functions in salt tolerance. Plant Physiol 134:528-538.

Lee M, Lee K, Lee J, Noh EW and Lee Y (2005) AtPDR12 contributes to lead resistance in Arabidopsis. Plant Physiol 138:827-836.

Martinoia E, Klein M, Geisler M, Bovet L, Forestier C, Kolukisaoglu U, Muller-Rober B and Schulz B (2002) Multifunctionality of plant $\mathrm{ABC}$ transporters - More than just detoxifiers. Planta 214:345-355.

Moons A (2003) Ospdr9, which encodes a PDR-type ABC transporter, is induced by heavy metals, hypoxic stress and redox perturbations in rice roots. FEBS Lett 553:370-376.

Multani DS, Briggs SP, Chamberlin MA, Blakeslee JJ, Murphy AS and Johal GS (2003) Loss of an MDR transporter in compact stalks of maize br 2 and sorghum dw3 mutants. Science 302:81-84.

Otani M, Shitan N, Sakai K, Martinoia E, Sato F and Yazaki K (2005) Characterization of vacuolar transport of the endogenous alkaloid berberine in Coptis japonica. Plant Physiol 138:1939-1946.

Otsu CT, daSilva I, de Molfetta JB, da Silva LR, de AlmeidaEngler J, Engler G, Torraca PC, Goldman GH and Goldman $\mathrm{MH}$ (2004) NtWBC1, an ABC transporter gene specifically expressed in tobacco reproductive organs. J Exp Bot 55:1643-1654.

Rai M (2006) Refinement of the Citrus tristeza virus resistance gene (Ctv) positional map in Poncirus trifoliata and generation of transgenic grapefruit (Citrus paradisi) plant lines with candidate resistance genes in this region. Plant Mol Biol 61:399-414.

Reymond P and Farmer EE (1998) Jasmonate and salicylate as global signals for defence gene expression. Curr Opin Plant Biol 1:401-411.

Rzhetsky A and Nei M (1993) Theoretical foundation of the minimum evolution method of phylogenetic inference. Mol Biol Evol 10:1073-1095.
Saitou N and Nei M (1987) The neighbor-joining method: A new method for reconstructing phylogenetic trees. Mol Biol Evol 4:406-425.

Sánchez-Fernández R, Davies TGE, Coleman JOD and Rea PA (2001) The Arabidopsis thaliana ABC protein superfamily, a complete inventory. J Biol Chem 276:30231-30244.

Santelia D, Vincenzetti V, Azzarello E, Bovet L, Fukao Y, Duchtig P, Mancuso S, Martinoia E and Geisler M (2005) MDR-like ABC transporter AtPGP4 is involved in auxinmediated lateral root and root hair development. FEBS Lett 579:5399-5406.

Sasabe M, Toyoda K, Shiraishi T, Inagaki Y and Ichinose Y (2002) cDNA cloning and characterization of tobacco ABC transporter: NtPDR1 is a novel elicitor-responsive gene. FEBS Lett 518:164-168.

Schiengold M, Schwantes L, Ribeiro MF, Lothhammer N, Gonzalez TP, Chies JAB and Nardi NB (2006) Expression of $m d r$ isoforms in mice during estrous cycle and under hormone stimulation. Genet Mol Biol 29:755-761.

Schmitz G, Langmann T and Heimerl S (2001) Role of ABCG1 and other ABCG family members in lipid metabolism. J Lipid Research 42:1513-1520.

Smart CC and Fleming AJ (1996) Hormonal and environmental regulation of a plant PDR5-like ABC transporter. J Biol Chem 271:19351-19357.

Stein M, Dittgen J, Sanchez-Rodriguez C, Hou B-H, Molina A, Schulze-Lefert P, Lipka V and Somerville S (2006) Arabidopsis PEN3/PDR8, an ATP-binding cassette transporter, contributes to nonhost resistance to inappropriate pathogens that enter by direct penetration. Plant Cell 18:731-746.

Stukkens Y, Bultreys A, Grec S, Trombik T, Vanham D and Boutry M (2005) NpPDR1, a pleiotropic drug resistancetype ATP-binding cassette transporter from Nicotiana plumbaginifolia, plays a major role in plant pathogen defense. Plant Physiol 139:341-352.

Tatusova TA and Madden TL (1999) Blast 2 sequences - a new tool for comparing protein and nucleotide sequences. FEMS Microbiol Lett 174:247-250.

Terasaka K, Blakeslee JJ, Titapiwatanakun B, Peer WA, Bandyopadhyay A, Makam SN, Lee OR, Richards EL, Murphy AS, Sato F, et al. (2005) PGP4, an ATP binding cassette P-glycoprotein, catalyzes auxin transport in Arabidopsis thaliana roots. Plant Cell 17:2922-2939.

Tusnády GE and Simon I (2001) The HMMTOP transmembrane topology prediction server. Bioinformatics 17:849-850.

van den Brûle S and Smart CC (2002) The plant PDR family of ABC transporters. Planta 216:95-106.

van den Brûle S, Muller A, Fleming AJ and Smart CC (2002) The $\mathrm{ABC}$ transporter SpTUR2 confers resistance to the antifungal diterpene sclareol. Plant J 30:649-662.

\section{Internet Resources}

CitEST database, http://citest.centrodecitricultura.br/.

PDR members of $A$. thaliana, http://www.arabidopsis.org/info/ genefamily/pdr.html.

Prediction of transmembrane helices and topology of proteins (HMMTOP), http://www.enzim.hu/hmmtop/.

GenBank BLAST, http://www.ncbi.nlm.nih.gov/blast.

Alignment of two sequences (GenBank), http://www.ncbi.nlm. nih.gov/blast/bl2seq/wblast2.cgi.

Associate Editor: Reinaldo Montrazi Barata 